\title{
LA POLITICA ECONOMICA DE CARLOS III ¿Fiscalismo, cosmética o estímulo al crecimiento? *
}

\author{
VICENT LLOMBART
}

Universidad de Valencia

\begin{abstract}
A Franco Venturi, per il suo lungo e fecondo peregrinare nel Settecento riformatore.

El intento de los dinosaurios de preservar el sistema (el deseo de volver al agua y de permanecer asi anfibios) condujo al cambio del propio sistema [el desarrollo de extremidades robustas y la invasión de la tierra].
\end{abstract}

Hirschman (1971)

\section{RESUMEN}

El objeto principal del trabajo consiste en analizar y valorar la acción económica del Estado en España durante el período 1760-1790. Tras sintetizar las principales interpretaciones críticas se estudian tres cuestiones fundamentales para la apreciación de toda política económica: 1. La exposición ordenada de los medios aplicados y la deter-

* El presente trabajo forma parte del proyecto de investigación «Pensamiento económico y reforma ilustrada» financiado por el Ministerio de Educación y Ciencia (DGICYT, PB90-0576). Un incipiente embrión del mismo se presentó en el Encuentro con Albert $\mathrm{O}$. Hirschman celebrado en la U.I.M.P (Santander) en julio de 1992. Agradezco los comentarios y observaciones que en aquella ocasión realizó el profesor Hirschman (así como los posteriores), las 23 puntualizaciones realizadas por Ernest Lluch tras una atenta lectura del texto y las estimulantes consideraciones de Francisco Comin, Fabián Estapé y Pedro Schwartz. Versiones preliminares del artículo se expusieron en los Seminarios de Historia e Instituciones Económicas de la Universidad de Valencia y de la Universidad Complutense de Madrid, en el Departamento de Economia Politica de la Universidad de Zaragoza y en el Seminario de Historia Moderna y Contemporánea de la Universidad de Pisa, en los que recogí tantas sugerencias y críticas que es imposible detallar. Deseo aludir a las también 23 sugerencias especificas realizadas por uno de los evaluadores anónimos de esta Revista que han permitido, junto con todas las anteriores críticas y observaciones, mejorar la redacción del texto y eliminar errores e incorrecciones. Todos los que permanecen son de exclusiva responsabilidad del autor, que en algunos casos se ha obstinado en mantener. 
minación de los fines perseguidos; 2 . El proceso politico de toma de decisiones y de ejecución, y 3. Las posibles consecuencias de todo ello para el crecimiento económico. La valoración positiva obtenida, aunque no exenta de penumbras e interrogantes, permite cuestionar algunos fundamentos de las visiones criticas actuales.

\section{ABSTRACT}

The object of this paper is to assess and analyze the economic policies of the Spanish Government between 1760-1790. After reviewing the major criticisms of the role of the State, three basic areas are considered. First, a survey of the principal measures introduced and their aims; second, the process of policy making and, three, the consequences of economic policy on growth. We suggest that perhaps some of the traditional interpretations of the role of the State in this period need to be re-examined.

Poco antes y poco después del día 14 de diciembre de 1788 —en cuya madrugada falleció Carlos III- Jovellanos y Cabarrús pronunciaron en la Sociedad Económica Matritense sendos Elogios del monarca ${ }^{1}$ en los que junto a los naturales pasajes panegíricos expusieron interesantes y arriesgados análisis del reinado. Ambos economistas ilustrados apreciaron de forma muy positiva la labor realizada, especialmente en el terreno económico, e insistieron en la necesidad de continuar en la misma dirección. Doscientos años después resulta curioso el contraste entre las apreciaciones de Jovellanos y Cabarrús - a las que se podrian añadir las de otros ilustrados- y las provenientes de una amplia gama de historiadores económicos y políticos actuales que, desde diferentes enfoques, se muestran proclives a presentar visiones marcadamente criticas de la política económica y de los programas de reforma de la época ilustrada.

El objeto del presente trabajo consiste en analizar la acción del Estado en el terreno económico durante el periodo 1760-1790. Tras sintetizar las principales interpretaciones críticas surgidas en la literatura reciente, se intentará analizar separadamente tres problemas que a menudo se entrecruzan: los objetivos de la política económica, los procesos políticos de toma de decisión y ejecución y los posibles efectos económicos de las decisiones tomadas. La conclusión obtenida está en líneas generales más próxima a la mantenida por Jovellanos y Cabarrús que a las de las visiones críticas actuales. La naturaleza del artículo y la necesidad de economizar espacio dejan fuera del análisis aspectos como la formación de la reforma, el estudio personalizado de las ideas econó-

'Jovellanos (1789) y Cabarrús (1789). 
micas que estimularon el comportamiento del Estado y el análisis cronológico detallado de la evolución del proceso ${ }^{2}$.

\section{ALGUNAS INTERPRETACIONES CRITICAS RECIENTES: FISCALISMO, COSMETICA Y FRACASO BIENINTENCIONADO}

De la literatura económica y política sobre la época de Carlos III surgida durante la última década es posible obtener tres modelos de interpretaciones criticas sobre la política económica ilustrada y que a efectos de exposición agruparé bajo las denominaciones de tesis fiscalista, tesis cosmética y tesis del fracaso bienintencionado. Se trata de tres tipos ideales, deliberadamente simplificados y que no se excluyen plenamente, pero que en su conjunto pueden sintetizar los rasgos esenciales de las visiones críticas actuales.

En síntesis, la tesis fiscalista sostiene una interpretación hacendística de los procesos de reforma económica del reinado de Carlos III, destacando que tales reformas estaban dirigidas básicamente a aumentar los ingresos de la $\mathrm{Ha}$ cienda Pública. Expuesta inicialmente alrededor de las dificultades financieras de la Monarquía absoluta se aplicó con contundencia al caso de la liberalización del comercio colonial insistiendo en que su objetivo básico era aumentar la recaudación de aduanas y no el de promover las actividades económicas ${ }^{3}$. La tesis adquirió un marcado tinte belicista a partir de análisis que tomando el presupuesto estatal como indicador primordial de las prioridades del monarca ilustrado sostenían que tales prioridades respondian al papel tradicional de potencia imperial y no al de promover el desarrollo económico de la nación ${ }^{4}$. En definitiva, se sostiene que el belicismo y el reforzamiento del poder del Estado provocaron fuerte endeudamiento e inflación y limitaron el crecimiento 5 .

Bajo el título de tesis cosmética sitúo una serie de contribuciones que tienen en común la consideración de que las medidas económicas adoptadas no pu-

2 Estas cuestiones han sido analizadas por el autor para varios procesos reformistas en un libro reciente (Llombart, 1992). Algunas de las ideas que se exponen en el presente trabajo pueden verse como desarrollo, reconsideración y reelaboración teórica del punto tercero de su epílogo.

${ }^{3}$ Fontana (1971, 1982 y 1987), Delgado (1986, 1987 y 1989), Tiroco y Fradera (1987).

4 Barbier y Klein (1985), Stein (1989) y Lynch (1991).

5 Como variantes singulares de la tesis fiscalista pueden considerarse el enfoque del Public Choice histórico aplicado al xviI español y que considera objetivos básicos de la política gubernamental el reforzamiento del poder y la búsqueda de rentas del gupo dominante (González, M. J., 1989) y el planteamiento patrimonialista que busca la explicación de la actividad gubernamental de la Monarquía y de sus limitaciones en la concepción de las antiguos Estados patrimonialistas (Fernändez Albaladejo, 1989 y 1992). 
dieron superar el carácter cosmético, decorativo o superficial porque su objetivo último era racionalizar o salvaguardar el denominado Antiguo Régimen (o el modo de producción feudal). Se admite que pudo haber acrecimiento lineal» pero no un «auténtico desarrollo» del capitalismo, que hubiera requerido transformaciones estructurales previas de la «sociedad feudal avanzada», como cambios en el régimen de propiedad de la tierra y en el reparto del poder político. $\mathrm{Y}$ a menudo se considera que las verdaderas intenciones de los reformadores permanecen ocultas tras la retórica oficial de las medidas adoptadas ${ }^{6}$.

$\mathrm{Y}$ en tercer lugar la tesis del fracaso bienintencionado hace referencia a un grupo numeroso de aportaciones diversas, generalmente sobre aspectos específicos de la politica económica, que no encuentran intenciones perversas o encubiertas en los objetivos de unas actuaciones gubernamentales que pudieron estar bien orientadas, y que aún consiguieron logros parciales, pero que diversas razones - conectadas con la propia estructura de la sociedad señorial o con las limitaciones de las propuestas - provocaron en última instancia el fracaso de unas reformas cuyas realizaciones efectivas quedaron muy alejadas de las pretensiones iniciales ?

Por distintos caminos y con diferentes relieves las tres tesis coinciden en destacar la futilidad de las reformas que no pudieron estimular realmente el crecimiento económico y que no lograron evitar la «Crisis» o incluso la «Agonía del Antiguo Régimen» al final del reinado. También han surgido diversas voces defendiendo la virtualidad de las medidas tomadas y subrayando la evolución positiva de la sociedad española en la época de Carlos III. Así, las aportaciones fundamentales y con sucesivas reelaboraciones de Pierre Vilar, de Gonzalo Anes, de Antonio Domínguez Ortiz, de José Antonio Maravall, de Ri-

6 Planteada inicialmente en el terreno ideológico por Antonio Elorza (1970), esta tesis ha alcanzado mayor difusión entre numerosos historiadores económicos a partir de los trabajos de Emiliano Fernández de Pinedo (1980), de Rodríguez Labandeira (1982), de Roberto Fernández Diaz (1985) y de los componentes del Equipo Madrid (1988). En un novedoso y consistente manual sobre la España del xvill, Roberto Fernández Diaz (1993) se aleja aún más de las tesis cosméticas simples aunque manteniendo al mismo tiempo, en forma matizada pero reiterada, el argumento de fondo de la tesis: la inviabilidad de obtener un «verdadero desarrollo capitalista» (más allá del mero crecimiento económico) por parte del reformismo ilustrado radicó en no acometer el cambio pleno de las relaciones de propiedad y producción de una sociedad «tardofeu. dalm.

7 Entre los historiadores que parecen simpatizar con esta tesis (y que en algunos casos y as pectos compatibilizan con las anteriores) es posible destacan, además de algunos trabajos anteriores del autor de este artículo (Llombart, 1976 y 1981), a González Enciso y Patricio Merino (1979), Pedro Voltes (1987), Concepción de Castro (1987), Felipa Sánchez (1988), Garcia Sanz (1989), Garcia Baquero (1989) y Luis Perdices (1993). 
chard Herr y de Pedro Tedde ${ }^{8}$, son muestra de líneas de investigación diferenciadas en sus conclusiones principales de las tres tesis anteriores. Naturalmente, el presente trabajo se ha visto beneficiado por tales aportaciones - iy también por las visiones criticas! - y pretende continuar su senda utilizando un tipo de aproximación específico.

\section{UNA RECONSTRUCCION RACIONAL: FINES Y MEDIOS DE LA POLITICA ECONOMICA ILUSTRADA (1760-1790)}

\section{II.1. Principales medidas y líneas de actuación}

Una de las formas más directas de aproximarse al contenido de la política económica de un período para obtener una visión de conjunto con economía de medios consiste en enumerar las medidas adoptadas. Como la época de Carlos III se caracterizó por su prolijidad legislativa ${ }^{9}$, parece conveniente seleccionar las medidas más relevantes y unificar las reiteraciones. Así se ha confeccionado el siguiente cuadro en torno a las 150 principales disposiciones, decisiones y actuaciones del gobierno español en materia económica desde 1760 a 1790, agrupándolas —en lo posible - sectorialmente y ordenándolas en cada sector por líneas principales de acción.

\section{CUADRO 1}

Relación de medidas de política económica (1760-1790)

POI.ITICA AGRARIA: 1. Liberalización del comercio y de los precios agrarios: abolición de la tasa cerealística (1765), libre comercio interior de granos (1765-1790) y alternativas sobre la exportación de granos (1765, 1769, 1783, 1787); liberalización de los precios de otros víveres (1767) y de los jornales en el campo (1767). 2. Dotación de tierras y estabilización de los labradores independientes: limitaciones a la subida de arrendamientos, a los subarriendos y a los desahucios $(1763,1764,1768,1770$ - elimina restricciones- y 1786); Repoblación de Sierra Morena (1767); repartos de tierras concejiles y baldias (1767-1770); incoación del inconcluso Expediente de Ley Agraria (1767-1795). 3. Eliminación de otros obstáculos al desarrollo agrario: intento fallido de limitación del crecimiento de las propiedades eclesiásticas (1766); reforma interna de la Mesta (1779-1782); prohibición de entrada de ganado en viñas y olivares (1779);

8 Vilar (1966, 1982 y 1992), Anes (1970, 1975 y 1989), Domínguez Ortiz (1976, 1988 y 1989), Maravall (1991), Herr (1964, 1989a y 1989b) y Tedde (1988 y 1989).

${ }_{9}$ Artola (1982), pp. 17-18, y Cabrera (1982), pp. 187-190. 


\title{
CUADRO 1 (continuación)
}

\author{
Relación de medidas de política económica (1760-1790)
}

permisión de cercar tierras de labor y arbolado sin licencia previa (1788); prohibición de fundar mayorazgos sin licencia real, no concedible a los menores de 3.000 ducados de renta (1789). 4. Difusión conocimientos e innovaciones técnicas: estudios y experimentos de las Sociedades Económicas, Jardín Botánico y otras instituciones; fomento de las ediciones, traducciones y prensa agrarias.

Politica Industrial: 5. Incentivos fiscales y bonorificos a las fábricas y las artes: gracias, exenciones y franquicias por ramas o clases de fábricas con progresiva generalización a todos los textiles $(1772,1773,1778,1779,1780,1781,1784,1786,1789)$; declaración de la honradez de todos los oficios (1783) y anulación del impedimento de ilegitimidad (1784). 6. Liberalización gradual del proceso de fabricación y reforma de los gremios: permiso de libre establecimiento de fábricas de jabón (1768); obligación a los gremios de admitir maestros extranjeros y autorización de la movilidad de oficiales nacionales (1777); permisibilidad en variación del proceso de producción en fábricas de seda (1778), lino y cáñamo (1784), lana y seda (1786) y sector textil (1789); protección de la formación y libre trabajo de las mujeres y niñas frente a los gremios (1779 y 1784). 7. Retroceso en el apoyo a las Fábricas Reales estatales: creación de la Real Fábrica de Porcelana del Buen Retiro (1759); cesión de varias Fábricas Reales estatales a compañías privadas $(1761,1762,1779,1785$ y 1786). 8. Fomento de la industria popular y de la industria militar: publicaciones oficiales estimulando la industria rural (1774-1777); Escuelas-fábrica de lienzo y de lana y Escuelas patrióticas de lino y cáñamo (1774-1786); ampliación de Reales Fundiciones de Cañones y de los astilleros y arsenales (1761-1783) y establecimiento de nuevas fundiciones de artilleria (1771 y 1777).

POLITICA COMERCIAL: 9. Liberalización y fomento del comercio interior y colonial: libertad de comercio y de precios de libros (1762), granos (1765) y otros viveres (1767); limitaciones de algunas restricciones de los gremios de comerciantes (1780); habilitación de nueve puertos españoles a comerciar con Islas de Barlovento y supresión del derecho de palmeo y otros (1765); ampliación a la Luisiana (1768), Yucatán y Campeche (1770) y a la región rioplatense (1778); Reglamento y aranceles para el comercio libre con las Indias (1778); extensión del Reglamento a Nueva España y Venezuela (1789). 10. Proteccionismo comercial e industrial: autorización de importación de tejidos de algodón con un arancel del 20 por ciento (1760); prohibición de importación de tales tejidos $(1768,1769,1770)$; restricciones o prohibición de la saca de materias primas españolas $(1760,1767,1772$ y 1774); libertad de derechos a la introducción de cáñamo y lino en rama y de los utensilios para su hilado (1775 y 1789); Arancel general proteccionista con derechos entre el 15 y el $30 \%$ (1782); creación de la Compañía de Filipinas (1785); autorización de importación de muselinas no pintadas (1789). 11. Tratados comerciales: Acuerdo comercial con Francia en Tercer Pacto de Familia (1761); Tratado de Paz, Pesca y Cornercio con Marruecos (1767, 1780); Tratado de Amistad y Comercio con Portugal (1778) y Tratado de Paz y Comercio con Turquia (1782).

PoltinCa FINANCIERA: 12. Desarrollo y saneamiento de mercados financieros: actualización de la normativa sobre crédito y financiación de la Carrera de Indias (1760, 1768 y 1770); reconocimiento de la legalidad de los tipos de interés en los contratos (1764); progresiva eliminación de las monedas de vellón y nuevas acunaciones de monedas de cobre puro, de oro y de plata (1771, 


\section{CUADRO 1 (continuación)}

\section{Relación de medidas de política económica (1760-1790)}

1772, 1779, 1786); emisión de Vales Reales (1780, 1781, 1782); creación del Banco de San Carlos (1782). 13. Estabilidad de la estructura fiscal: abolición de la bolla catalana y sustitución por un derecho de aduana (1770); abandono definitivo del proyecto de Unica Contribución (1776); aumento de un tercio del cupo a recaudar por rentas provinciales y equivalentes (1780-1783); rebaja de los tipos efectivos de alcabalas, cientos y millones, revisión de encabezamientos e introducción del sistema de cuenta y razón (1785) y Contribución de frutos civiles (1786). 14. Economía relativa del gasto público: evolución moderada según las cuentas presupuestarias del periodo $1760-1790$.

POLITICA DE OBRAS PÚBLICAS Y COMUNICACIONES: 15. Creación y mejora de infraestructuras $y$ servicios de transporte, comunicación y regadio: decreto proyectando construcción de red de caminos reales (1761) desarrollado a lo largo del reinado; Mejora del servicio de Correos y Postas (1762, 1779); establecimiento de un correo marítimo regular entre España e Indias (1764); Medidas de mejora de la seguridad y comodidad del tráfico (posadas y mesones); Canal del Manzanares (1770); Canal Imperial de Aragón (1768-1790); Canal de Castilla (1753-1791); obras complementarias como caminos de rueda, puentes, presas, acueductos y regadios; ampliación y refuerzo de puertos; construcción de edificios públicos.

OTRAS MEDIDAS: 16. Creación de instituciones económicas y cientificas: Sociedades Económicas de Amigos del Pais (1764, 1775-1789), Juntas Particulares y Consulados de Comercio (17581766 y 1784 -1786) y promoción cientifica y cultural. 17. Policía de pobres: recogidas de vagos y mal entretenidos $(1767,1775,1776,1785)$, reorganización y ampliación de los hospicios y hospitales (1767 y otros). 18. Fomento directo de la población: estimulos a la nupcialidad (1776), prácticas de inoculación (1771) y medidas contra el paludismo (1784, 1787); Censo de Floridablanca (1787).

FUENTE: Elaboración propia a partir de Novisima Recopilación (1805-1807), Colecciones de Ordenes Generales y Reales Cédulas del A.H.N., Matilla (1956), Sánchez (1792), González Enciso (1980), Rodríguez Labandeira (1982), Anes (1989), Llombart (1992) y otras noticias dispersas.

La existencia de publicaciones que describen particularizadamente las principales medidas ${ }^{10}$ permite centrar este apartado en comentarios interpretativos de carácter genérico. En una primera aproximación el cuadro de medidas muestra la amplitud y generalidad de una política económica que abarca a todos los sectores sin discriminación aparente y el carácter moderado y gradualista de la política. También puede observarse, desde un punto de vista cronológico, que el periodo comprendido entre 1763 y 1770 fue el de la pues-

10 Entre las que destacan las de Rodriguez Labandeira (1982), Gonzalo Anes (1989) y Garcia Sanz (1989). 
ta en marcha de los proyectos liberalizadores y reformistas más ambiciosos y de mayor insistencia en la política agraria, mientras que a partir de 1775 predominaron las medidas industriales y arancelarias junto a la continuación de los proyectos anteriores. Asimismo, puede deducirse el predominio relativo de una política de ordenación - «Ordnungspolitik» en la terminología alemana- sobre la de participación directa del gobierno en las actividades y procesos económicos-«Prozesspolitik» "'. En realidad, esta caracteristica importante de la política económica del período se debe, por una parte, a la escasez de instrumentos de regulación e intervención que eran utilizados por los países europeos en el siglo xviII y, por otra, al cambio de criterio que en ciertos aspectos se adoptó respecto a la política de intervenciones más directas de los reinados de Felipe V y Fernando VI - como por ejemplo en las fábricas reales, en las compañias comerciales o en el comercio colonial.

Al observar con mayor detenimiento el contenido y significado de las diferentes líneas de actuación del reinado de Carlos III, puede comprobarse que muchas de ellas parecen responder a criterios de actuación semejantes pero aplicados a diferentes sectores económicos. Así, me atrevería a sintetizar de la siguiente manera los principales principios impulsores de la política económica que en buena parte coinciden con el pensamiento económico de autores como Campomanes, Olavide, Floridablanca, Múzquiz y Cabarrús, diseñadores y ejecutores de tal política. 1. La liberalización económica interior y de los intercambios coloniales: suponia la eliminación de las leyes, privilegios y monopolios que se oponian al comercio libre en el marco geográfico de la monarquía española (líneas 1 y 9), la mitigación de otros estorbos que en el planteamiento ilustrado se oponían a la agricultura (línea 3), el paulatino reconocimiento a costa de los gremios de la libertad de fabricación y ocupación y la marcha atrás respecto a las Fábricas Reales (líneas 6 y 7) y el desarrollo de los mercados financieros y el de las infraestructuras de transporte (lineas 12 y 15) que debian permitir, junto con las anteriores lineas, el abaratamiento de los costes de transacción. 2. Proteccionismo exterior: regulación de las relaciones económicas con el resto del mundo para preservar el mercado nacional (linea 10). 3. Intervenciones de fomento: adopción de otras intervenciones públicas de fomento y estímulo de determinadas actividades económicas o de corrección de problemas sociales (lineas $2,5,8,17$ y 18); en general, estas intervenciones no se dirigian a convertir al Estado en agricultor, fabricante o comerciante, sino a establecer un marco juridico para crear las condiciones y estímulos del desarrollo de tales actividades. 4. Estabilidad de la Hacienda Real: (líneas 13 y 14) que experimentó una

\footnotetext{
11 Sobre esta distinción, Hutchison (1971), pp. 142-144.
} 
cierta aversión a los cambios fiscales y un crecimiento moderado tanto de los ingresos como de los gastos públicos -excepto en los años de la Guerra de Independencia americana-. Y 5. Difusión de conocimientos útiles: preocupación creciente de los poderes públicos por el progreso y difusión de las «ciencias útiles» - de la «economía política» como «ciencia del gobierno» en particular- y de las innovaciones técnicas que se consideraban aplicables a los procesos productivos (líneas 4 y 16).

\section{II.2. Objetivos económicos y fines políticos}

Es posible obtener por inducción una relación de los objetivos económicos pretendidos por la política del periodo, que busca también ser útil y significativa respecto al proceso de toma de decisiones. Así, se puede identificar un primer grupo de cuatro objetivos económicos básicos que eran perseguidos por sus efectos directos sobre el bienestar económico: la expansión de la producción agrícola e industrial, el desarrollo del comercio y las comunicaciones, el fomento de la ocupación y la población y la mejora en la distribución de la renta y la riqueza. A ellos habría que añadir otros dos objetivos económicos que tendrían un cierto carácter instrumental, pues se buscaban principalmente por sus efectos sobre los anteriores objetivos: la mejora en la balanza comercial y la suficiencia financiera. El crecimiento de las exportaciones de bienes y servicios sobre las importaciones más que como un fin en sí mismo se pretendía por sus efectos favorables en el nivel de producción y ocupación nacionales, aunque tendría la ventaja añadida - según la mentalidad de la época - que ello se conseguiría «a costa del vecino». Con la suficiencia financiera se intentaba avanzar hacia una situación de equilibrio presupuestario que garantizase la solvencia de la Hacienda Real para hacer frente a sus compromisos. Se podría sintetizar el análisis señalando que a través de los principios de liberalización económica interior, proteccionismo respecto al exterior y determinadas intervenciones reguladoras se pretendía desarrollar las actividades productivas y comerciales, aumentar la población y mejorar la distribución de la renta y la balanza comercial.

Podemos presentar el esquema expuesto tomando como uno de los objetivos básicos de la política económica del período la consecución de una mayor Riqueza de la nación. El objetivo Riqueza hace referencia a una mayor producción y abundancia de bienes, a una mayor generación de ingresos y a una ampliación de la ocupación productiva para una población creciente. El concepto concernia tanto a la riqueza per cápita como a la riqueza nacional que se obte- 
nía agregando la riqueza individual, y ésta se prefería que se repartiese entre el mayor número posible de personas. Junto a ese objetivo económico básico hemos de situar un objetivo político que orientaba también la acción del Estado: la Fortaleza de la Monarquia. Tal Fortaleza había que obtenerla tanto en el plano exterior - a través de la política de defensa nacional, de mantenimiento de las posesiones americanas y de afirmación respecto a la autoridad eclesiástica romana - como en el del reforzamiento interno buscando seguridad y estabilidad social y la unificación, centralización y desarrollo de la Administración.

\section{CUADRO 2}

Asignación del gasto público en Inglaterra y en España, 1756-1792

\begin{tabular}{|c|c|c|c|c|c|c|}
\hline & \multicolumn{3}{|c|}{ Inglaterra } & \multicolumn{3}{|c|}{ España } \\
\hline & $\begin{array}{c}\text { Gastos } \\
\text { defensa } \\
\%\end{array}$ & $\begin{array}{c}\text { Gastos } \\
\text { civiles } \\
\%\end{array}$ & $\begin{array}{c}\text { Deuda } \\
\%\end{array}$ & $\begin{array}{c}\text { Gastos } \\
\text { defensa } \\
\%\end{array}$ & $\begin{array}{c}\text { Gastos } \\
\text { civiles } \\
\%\end{array}$ & $\begin{array}{c}\text { Deuda } \\
\%\end{array}$ \\
\hline $1756-1763$ & 70 & 8 & 22 & $55^{*}$ & $25^{\mathrm{a}}$ & $20^{\mathrm{a}}$ \\
\hline $1764-1775$ & 37 & 20 & 43 & 59 & 25 & 16 \\
\hline $1776-1783$ & 62 & 8 & 30 & 63 & 21 & 16 \\
\hline $1784-1792$ & 31 & 13 & 56 & 57 & 24 & 19 \\
\hline
\end{tabular}

a Datos referidos al periodo 1760-1763. Se ha aplicado el criterio señalado por Barbier-Klein (1985), p. 478, para no contabilizar doble el extraordinario de 1761.

Fuentes: Para Inglaterra O'Brien (1988), p. 2, tabla 1; para España: elaboración a partir de José Patricio Merino (1987) y Pedro Tedde (1989), pp. 143-146, cuadros 1 a 3.

La tesis fiscalista-belicista ha tendido a considerar que los elevados gastos militares y el fuerte endeudamiento de la Monarquia española se constituyeron en obstáculos intrínsecos a la reforma interior y al progreso. Sin embargo, cuando observamos la historia financiera europea del siglo podemos comprobar sin dificultad alguna cómo la estructura del gasto público de los diferentes presupuestos estatales estaba preponderantemente dominada por los gastos militares, de tal forma que los gobiernos europeos utilizaban buena parte de sus ingresos en sostener sus compromisos militares y en financiar una deuda que constituia esencialmente un gasto militar diferido ${ }^{12}$. Los presupuestos no

12 Mathias-O'Brien (1976), O'Brien (1988) y Velde-Weir (1992). 
hacian más que reflejar el carácter belicista de un siglo en el que entre 1700 y 1815, Inglaterra, Francia y España estuvieron más de la mitad de los años en guerra entre sí y en el que Charles Tilly ha calculado que los 17 conflictos mantenidos por el total de las grandes potencias mundiales provocaron que el 78 por ciento de años fueran de carácter bélico ${ }^{13}$. En esas condiciones, una cierta predisposición al fiscalismo no sólo parecía razonable, sino que su ausencia hubiera constituido una temeridad, tanto política como económica.

Ahora bien, una simple y directa comparación de la distribución del gasto público presupuestario de Inglaterra y de España entre gastos militares, civiles y el servicio de la deuda nos puede ayudar a obtener una visión más precisa en términos relativos.

Aun con las cautelas imprescindibles en estas comparaciones internacionales que pueden ocultar algunas diferencias en los criterios de contabilización, se puede afirmar con suficiente margen que en términos relativos en España hubo mayor estabilidad en las oscilaciones de los gastos entre guerra y paz, menor endeudamiento y un esfuerzo bastante más elevado hacia la administración civil - porcentajes relacionados con el menor belicismo relativo del reinado de Carlos III medido en años de guerra-. Teniendo en cuenta el fuerte crecimiento de la recaudación impositiva experimentada en Inglaterra ${ }^{14}$, las cifras anteriores ponen de manifiesto un relativo belicismo, fiscalismo y endeudamiento británicos, precisamente el pais donde al parecer mayor crecimiento económico se produjo en el setecientos, revelendo a los contemporáneos que la creación de riqueza y el desarrollo de la potencia del Estado eran claramente compatibles.

No se trataba sólo de que los gastos militares podían estimular directamente determinadas actividades productivas, podian favorecer la aparición o difusión de externalidades tecnológicas e incluso podian considerarse como inversiones «mercantilistas» protectoras de los mercados coloniales, sino que en el siglo xviII asistimos a una de las fases más acuciantes de competencia y rivalidad - tanto militar como económica y tecnológica- en el seno del sistema europeo de Estados nacionales, en el que la debilidad de un gobierno no sólo podía generar grandes pérdidas económicas, sino amenazar su propia integridad o supervivencia ${ }^{15}$. Un observador tan perspicaz y poco militarista como Adam Smith, tras señalar que la primera obligación del Soberano era la defensa remarcaba que el «principal objeto de la economía politica de todo país consiste en aumentar la riqueza y el poder del pais», precisando que el poder de-

13 Tilly (1992), p. 116.

14 Mathias-O'Brien (1976) y O'Brien (1988)

is Jones (1987), pp. 149-196. 
pendia de la riqueza, pues era del producto anual de la nación de donde procedian en último término todos los impuestos ${ }^{16}$.

Asi pues, para el caso español y en las condiciones geopolíticas del xvIII no existia en absoluto incompatibilidad entre los fines de fortaleza de la monarquía y riqueza de la nación, sino que más bien resultaban ser complementarios. Incluso puede obtenerse una relación más amplia a la señalada por Smith. No sólo la riqueza era el fundamento principal de la fortaleza o potencia de la nación, a través de la mayor base imponible, la mayor población susceptible de reclutamiento militar, las mejores comunicaciones, el desarrollo de la navegación a tierras lejanas y las mejoras en los circuitos de crédito. Sino que al mismo tiempo la propia fortaleza se constituia en un elemento estimulador de la riqueza, pues tal fortaleza era necesaria para defender la nación y mantener su estabilidad social, para sostener los mercados coloniales y dar seguridad a los intercambios, para perseguir el contrabando, la pirateria y el bandidaje, para firmar buenos tratados internacionales, para promover el desarrollo científico y tecnológico, para adoptar una política de reformas interiores y sobre todo para hacerla cumplir.

\section{III.3. Un desequilibrio inicial hirschmaniano}

Como señaló Hirschman ${ }^{17}$ para otro contexto más reciente, la interrelación entre riqueza y potencia nacional no constituye un círculo vicioso si se consigue un inicial desequilibrio en la distribución de poder en favor de una nación que lo utilizara, por ejemplo, para ampliar su comercio colonial e introducir asi un efecto acumulativo al reforzar su posición inicial de poder. En el caso de la España de Carlos III, ese desequilibrio inicial hirschmaniano para salir de una situación de atraso y de debilidad política respecto a sus vecinos se planteaba en el terreno económico más que en el del poder, pues la nación poseía ya un inmenso imperio colonial que sólo pretendía defender y aprovechar. Si se conseguía romper favorablemente el equilibrio existente entraria en funcionamiento un efecto acumulativo entre riqueza y fortaleza que posibilitaría el progreso de la nación y su reforzamiento en el concierto de potencias euro. peas.

Para nuestros ilustrados el desequilibrio o empuje inicial se debería conseguir reactivando y utilizando productivamente los dos factores de producción

it Smith (1776), p. 335.

17 Hirschman (1945), pp. 13-16). 
básicos -el trabajo y la tierra - de los que se pensaba que existía un amplio nivel de recursos ociosos. A partir de un positivo optimismo sobre las posibilidades de crecimiento de la economía española se consideraba que existia un elevado margen - y una elevada «tensión» para utilizar la expresión de Gerschenkron ${ }^{18}$ - entre la situación existente y los beneficios potenciales que se derivarian de una adecuada política de reformas que por medio de la eliminación progresiva de monopolios, privilegios y restricciones en la economía nacional y en el imperio, y por medio de diversas medidas de fomento originara un aumento de la riqueza, de los intercambios y de la ocupación y una mayor integración económica. La mayor libertad económica operaba dentro de un marco de estricto proteccionismo respecto al resto del mundo que no se ponia en cuestión en el terreno del pensamiento, ni mucho menos en el de la politica aplicada.

Con frecuencia se ha afirmado que España adoptó una «política mercantilista» tardiamente cuando ya otros países estaban abandonando la experiencia. La suposición subyacente de que otros paises como Inglaterra o Francia ya habían apostado por un modelo de free trade se ha ido mostrando cada vez menos realista. Ralph Davis insistió en que «The Rise of Protection in England» se desarrolló especialmente entre 1689 y 1789, coincidiendo los momentos más intensos con los años de redacción y publicación de la Riqueza de las Naciones ${ }^{19}$. En Francia, mientras los fisiócratas se empeñaban en proclamar un radical liberalismo económico, Luis XV (y después su sucesor) se inclinaría por políticas intervencionistas de tintes colbertistas ${ }^{20}$. Sólo en Prusia y en Austria parecía existir una mayor concordancia entre el pensamiento económico cameralista y la política económica intervencionista adoptada por Federico II, María Teresa y José II. Excepto el peculiar caso holandés (que sufrió un relativodeclive en el siglo XVIII), lo que variaba de pais a país era el grado de intensidad del proteccionismo y para una nación como España una política librecambista estaba más allá del margen posible de decisión política.

Naturalmente, para los reformadores ilustrados españoles aquel empujón inicial hirschmaniano sólo lo podía dar el Estado. Únicamente un monarca fuerte y benevolente al frente de una Administración reforzada y con un poder eminente podia eliminar inicialmente los obstáculos que se oponian al crecimiento. No creían que fuerzas espontáneas o naturales pudieran cambiar las leyes, eliminar los privilegios y establecer las condiciones para el desarrollo de la actividad económica. Paradójicamente, era la mano visible e ilustrada del mo-

18 Gerschenkron (1970), p. 11.

19 Davis (1966), p. 314.

20 Deyon y Guignet (1980), pp. 611-632, y O'Brien, Griffiths and Hunt (1991), pp. 415-418. 
narca absoluto la que debía determinar autoritariamente las condiciones para que algo similar a la mano invisible smithiana pudiera operar en el marco nacional. Era el Estado el que debía imponer una ampliación del mercado, al tiempo que vigilaba politica y policialmente para reducir las fuertes resistencias que la gradual libertad económica encontraba. En definitiva, traduciéndolo a términos actuales, más Estado y más Mercado en el ámbito de un sólo país pueden considerarse como las máximas generales del gobierno económico de Carlos III.

El análisis expuesto no supone que establecidos los fines resulten determinados los medios, sino que más bien fue la opción que se tomó por determinados instrumentos la que permite reconstruir los objetivos y las características de la política económica. Adaptando los términos de Hirschman-Lindblom ${ }^{21}$, podríamos afirmar que la mejor comprensión de los asuntos tratados, la voluntad de reforma inspirada en valores morales y políticos y la disponibilidad de una Monarquia absoluta favorable, posibilitaron la apertura de algunos nuevos caminos ante viejos problemas.

\section{LA TRAMA POLITICA DE LA REFORMA ECONOMICA: DOS CASOS SUBSTANCIALES}

El esquema anterior está construido con el fin de obtener un modelo básico de referencia y mostrar la lógica subyacente del conjunto. Sin embargo, cualquier esquema de fines y medios tiende siempre a presentar las cosas más ordenadas de lo que realmente fueron. Es conveniente pues complementarlo con el análisis interno del proceso político de elaboración y ejecución de las decisiones, que constituye un aspecto esencial en la fragua de cualquier reforma y un condicionante fundamental de su alcance. Mostraré algunos rasgos básicos de dos casos substanciales ${ }^{22}$.

\section{III.1. Una victoria controvertida: el libre comercio de granos}

Es generalmente admitido que la promulgación el 11 de julio de 1765 de la Real Pragmática liberalizadora del comercio de granos constituyó una de las piezas centrales de la política económica del período. El proceso político con-

\footnotetext{
21 Hirschman (1988), pp. 362-366.

22 Una exposición más detallada y documentada de los procesos que sintetizo a continuación, en Llombart (1992), caps. 4 y 5.
} 
sistió en la tenaz defensa durante un cuarto de siglo de una victoria ajustada obtenida al principio del mismo. La medida fue preparada en 1764 por Esquilache y Campomanes con el acuerdo de Carlos III, y suponia eliminar la tasa de los precios de los cereales vigente en las regiones castellano-andaluzas, despenalizar el comercio de almacenamiento y reventa, suprimir algunos privilegios de los pósitos y ampliar el margen para el comercio exterior de los cereales. La liberalización fue polémica desde el principio: asi, en la sesión del Consejo de Castilla del 29 de marzo de 1765, que debía elevar la Consulta al rey, Campomanes sólo consiguió convencer a once de los veintidós consejeros presentes en cuanto a la libertad de comercio interior. Carlos III decidió promulgar la Pragmática liberalizadora, aunque su postura resuelta no pudo evitar que la historia posterior estuviera plagada de obstáculos, incidentes y dificultades en su aplicación. Tres tipos de resistencias pueden distinguirse: 1, las provenientes de la mentalidad popular manifestada en forma de protestas y graves motines (especialmente en 1766 y 1789): siguiendo el modelo generalizado por toda Europa y ante la grave situación de las subsistencias en los años de crisis, tal mentalidad mantenía una teoría conspiratoria de los precios atribuyendo la carestia y escasez de los granos a la codicia y manipulación de los comerciantes y a la ineficacia del gobierno; 2 , las múltiples reacciones hostiles en forma de quejas, informes, representaciones y hasta defecciones de las autoridades provinciales y locales que en forma mayoritaria participaban de aquella mentalidad anticomercial y reclamaban la vuelta al antiguo sistema, y 3, la propia oposición del Consejo de Castilla como institución que votó por unanimidad en 1770 contra la política liberalizadora y de nuevo elevó una Consulta al rey en 1775 solicitando la derogación de la Pragmática y el restablecimiento de las antiguas leyes castellanas. Sólo la decisión última de Carlos III de hacer caso omiso de su propio Consejo y de apoyar la posición muy minoritaria en la misma Administración del grupo reformador impidió la vuelta al pasado. En 1790, desaparecido Carlos III y estallada la Revolución Francesa, la Pragmática fue recortada con la supresión del libre comercio interior (al mismo tiempo que fue recortado el otro gran experimento liberalizador europeo: el de la Toscana de Pietro Leopoldo).

\section{III.2. Un ensayo incompleto: el comercio libre a Indias}

También existe acuerdo en que la otra pieza central de la política económica radicó en el proceso de liberalización del comercio colonial. Nos encontramos ahora ante un proceso politico con una dinámica inversa, consistente 
en graduales avances liberalizadores hacia un sistema de comercio libre nunca completado. El fundamento doctrinal inicial del proceso se encuentra en las Reflexiones sobre el Comercio Español a Indias que Campomanes redactó en 1762 y en las que proponía una radical reforma de la organización del comercio colonial hispano-americano, que debia basarse en el principio de la libertad comercial en el interior del monopolio español respecto al resto del mundo. Esta propuesta original de pleno comercio libre suponía: 1, la supresión del privilegio exclusivo del puerto de Cádiz; 2, la abolición del sistema de flotas y galeones y sustitución por el de navíos sueltos; 3, la autorización de comerciar a todos los puertos peninsulares sin necesidad de habilitación especifica; 4, la reducción de los derechos arancelarios, especialmente los recayentes sobre productos españoles, y supresión de los impuestos de palmeo y toneladas, y 5, la revocación de los privilegios de las compañias comerciales y del resto de restricciones al tráfico. Tras la Paz de París, que puso fin a la Guerra de los Siete Años evidenciando la supremacia inglesa, se pone en marcha el proceso reformista: como prólogo en 1764 se establece el Correo maritimo regular entre España y las Indias y al mismo tiempo Esquilache reúne una Junta para estudiar los problemas del sistema colonial, en la que participan Campomanes, Ortiz de Landázuri, Francisco Carrasco y otros, y que concluye con un informe de Ortiz proponiendo un sistema que podriamos denominar de cuasi comercio libre: 1 , habilitar el comercio directo a 14 puertos peninsulares y a 35 indianos; 2, fin de las flotas e intensificación de los navios sueltos; 3 , fuerte reducción de impuestos (exención de productos españoles y 6 por ciento sobre los extranjeros) y supresión del derecho de palmeo; 4 , introducción libre de esclavos en Indias por buques y negreros españoles, y 5 , reducción de trámites burocráticos.

Sin embargo, y posiblemente debido a la oposición del Consejo de Indias, a las resistencias de los Consulados de Cádiz, México y Lima y quizá a los propios tratados internacionales, el primer decreto liberalizador aprobado en octubre de 1765 acordó: 1, habilitar sólo 9 puertos españoles para comerciar únicamente con las Islas caribeñas de Barlovento; 2, refundir los impuestos en un 6 por ciento para los productos nacionales y un 7 por ciento para los extranjeros, eliminando el derecho de tanteo, y 3, suprimir trámites burocráticos. Así pues, este primer decreto supuso un ensayo minorado de comercio libre, circunscrito a una pequeña región del imperio. Se realizaron algunas ampliaciones, varios economistas ilustrados insistieron en la necesidad de generalizar el proceso y en diciembre de 1776 Ortiz de Landázuri, a instancias del rey, presentó un informe al Consejo de Indias para proceder a la ampliación del ensayo en el que proponía: 1, consolidar la extensión del comercio a 15 puertos habilitados españoles y 34 americanos; 2, reforma y homogeneización tributaria (exen- 
ción de derechos a la exportación de productos nacionales y a la entrada y venta en Indias, y rebaja en los retornos); 3, agilización de trámites y licencias; 4 , introducción libre de negros, y 5 , imposibilidad de que las compañías privilegiadas participasen en el comercio general. Quizá Ortiz, buen conocedor del Consejo de Indias al ser su contador general, se autolimitó en la propuesta al mantener la vigencia de las flotas de Nueva España. A pesar de tratarse de un comercio libre reducido respecto a su anterior informe de 1764 , la propuesta sólo consiguió uno de los siete votos de los consejeros y, al ser elevada al rey, aún fue reducida en la no habilitación de 4 puertos españoles y 11 americanos (con lo que la región de Venezuela quedó también excluida) y en la moderación de la reducción de impuestos. Así nació el famoso Reglamento y Aranceles Reales para el Comercio Libre del 12 de octubre de 1778 que, a pesar de su nombre y de su importancia estratégica, se trataba de una consolidación de lo ya legislado y de una reducción arancelaria homogénea, y no suponía más que un comercio libre mutilado, pues, entre otras razones, dejaba fuera las regiones de Nueva España y de Venezuela (alrededor de un 35 y de un 10 por ciento del tráfico, respectivamente) ${ }^{23}$.

Una década después aparecen nuevas discrepancias en el Consejo de Indias, se abre una encuesta entre las instituciones comerciales y se decreta en febrero de 1789 la extensión del Reglamento a Nueva España y a Venezuela, se conceden nuevas franquicias de derechos y se liberaliza para algunas zonas la introducción de negros. Aunque se avanzó en la liberalización, no se llegó a eliminar el sistema de puertos habilitados ni muchos de los monopolios y restricciones comerciales existentes tanto en España como en América, por lo que se puede afirmar que en el interior del monopolio español el pleno comercio libre nunca existió, ni siquiera en 1789 cuando comenzaba a ser demasiado tarde, pues las décadas posteriores se mostrarian muy poco propicias a un tranquilo comercio. Estamos pues ante un ensayo incompleto, cuyo alcance se vio principalmente limitado por los intereses comerciales privilegiados y por instituciones de la propia Administración, como el Consejo de Indias, que se hicieron eco de los mismos.

En otras muchas acciones reformistas se puede encontrar la impronta de la oposición y la obstrucción (y hasta la acción de la Inquisición). Algún escollo fue tan pronunciado - al menos a los ojos de un monarca moderado como Carlos III - que condujo a una derrota momentánea, como ocurrió en 1766 con el intento de limitación del crecimiento de los bienes de la Iglesia. Todo ello pertenece a la naturaleza de la política, pues cualquier reforma que se pre-

${ }_{23}$ Fisher (1987), pp. 30-35. 
cie produce resistencias y descalificaciones al perjudicar, al menos al principio, la posición absoluta o relativa de algún grupo social. ¡Y esta es otra forma de advertir el carácter no cosmético de la misma! Sin embargo, no es realista olvidar esa trama a la hora de valorar los efectos y el propio carácter de la reforma.

\section{POLITICA ILUSTRADA Y CRECIMIENTO ECONOMICO: LUCES Y PENUMBRAS DE UN PERFIL POSITIVO}

Existen serias dificultades para establecer un balance significativo de la política económica del período a través de una mera comparación mecánica entre los propósitos proclamados y los resultados efectivos observados. Múltiples elementos entorpecen esa pretensión aparentemente razonable: la ausencia de cuantificación de los objetivos y de los instrumentos, el telón de fondo de dinámicas autónomas y de variables coyunturas económicas no determinadas por las actuaciones estatales, los graves problemas para la identificación precisa de los efectos específicos de cada medida (dificultad casi insuperable para las abundantes medidas de ordenación), las modificaciones introducidas en los propios procesos políticos de decisión y ejecución y la posible aparición de efectos retardados, indirectos y colaterales. Además, la curiosa combinación señalada por Hirschman que suele acompañar a los procesos reformistas entre «efectos buscados pero no encontrados» (expectativas ilusorias estimuladoras de la acción) y «efectos no buscados pero encontrados» (consecuencias imprevistas de las acciones) ${ }^{24}$ origina por si sola que la tarea no sea susceptible de conclusiones inequivocas. Ante tales condiciones, agravadas por la escasez de estudios específicos, quizá sea mejor abandonar la perspectiva drástica y mono-factorial del éxito o fracaso, para preguntarse más matizadamente si la politica económica del reinado de Carlos III pudo constituir un obstáculo o un estimulo para un crecimiento que en cualquier caso vendría afectada por otros factores ajenos a la voluntad del gobierno. Desde esa perspectiva realizaré un breve repaso a las principales líneas de actuación para proponer una valoración que considere también las alternativas presentes en la arena política.

El libre comercio de granos. Los dos aspectos más innovadores de la medida fueron la abolición de una tasa doblemente discriminatoria - la de los intereses agrarios que no podían eludirla y la de las regiones castellano-andaluzas respecto a las litorales - y la despenalización del comercio interior de almace-

\footnotetext{
24 Hirschman (1978), pp. 134-135.
} 
namiento y reventa, lo que suponia una disminución del coste de transacción de los que se acogieran al nuevo marco legal. Diversos estudios empíricos y teóricos sobre la producción y los precios de los granos en las economías preindustriales han establecido — en base a ley King-Davenant - una relación inversa y más que proporcional de los precios ante las variaciones de las cosechas al ser un producto de primera necesidad cuya demanda era marcadamente inelástica ${ }^{25}$. En esas condiciones los efectos de una tasa que fuera efectiva consistían en imponer una drástica reducción de los ingresos agrarios, desestimular la producción y crear mayor escasez. Efectos que se verian agravados si se impedia el libre almacenamiento y compra-venta de la producción neta comercializable, pues al entorpecer la dispersión geográfica y temporal de los riesgos se aumentaba la dependencia respecto a los resultados locales de las cosechas y se dificultaba la integración de los mercados, la división social del trabajo y el crecimiento agrario. Entre las dos alternativas planteadas en el proceso de decisión español (como se plantearon tambièn con diferentes relieves y desenlaces en Francia, Toscana, Milán, Nápoles, Prusia e incluso Inglaterra) la opción más favorable para el crecimiento económico era el libre comercio, aunque su materialización no consiguiera todo lo que pretendia y sus efectos positivos inmediatos fueran moderados al estar condicionados por el ambiente de hostilidad, por la debilidad de las estructuras comerciales de diferentes regiones y quizá por las cautelas de la propia ley ${ }^{26}$.

El comercio libre a Indias. Consistió en un paquete de medidas que abría posibilidades antes cerradas al crecimiento comercial y económico de ambos lados del Atlántico al liberalizar progresivamente el sistema de intercambios de bienes y mejorar las comunicaciones en el seno del Imperio. Ampliar el régimen de intercambios libres y protegidos al conjunto del sistema colonial suponía una drástica reducción del coste de las transacciones basada en la obtención de nuevos o más amplios mercados para los productos españoles y coloniales, de aumentos en la velocidad del tráfico, de más ágiles comunicaciones, de menores y más justos aranceles y de mayores volúmenes de comercio. Todo ello implicaba una mayor integración económica (y también política) y afectaba favorablemente a las posibilidades de crecimiento, aunque natural-

25 Me estoy refiriendo a los trabajos iniciados por Gregory King y Charles Davenant, continuados por Thomas Tooke y W. S. Jevons y ratificados por los especialistas actuales. Jevons propuso una fórmula matemática para expresar que «el precio del trigo varía de forma inversa al cuadrado de la oferta, siempre que esta oferta no sea anormalmente pequeña». Todo ello implicaba que los agricultores mejoraban sus ingresos en los años de cosecha escasa. Para una discusión de este punto, considerando también la distinción entre producción bruta y neta, puede verse Wrigley (1992), pp. 134-185.

26 Castro (1987). 
mente cada área territorial aprovecharía esa posibilidad en función de su capacidad propia, de las restricciones que operasen en su situación interna que sería iluso pensar que desapareciesen de repente por crear un instrumento adecuado para el desarrollo. Los estudios recientes muestran una clara tendencia ascendente del volumen del tráfico entre España y América durante el último cuarto del siglo ${ }^{27}$, por lo que también parece en este caso que las ventajas estaban del lado del pretendido comercio libre respecto al viejo sistema privilegiado de flotas y galeones. Los datos proporcionados por Leandro Prados sobre el crecimiento de las exportaciones al resto del mundo indican además que no debió producirse un efecto desviación de comercio ${ }^{28}$. Por último, es preciso recordar que las cifras manejadas sobre el comercio colonial están en realidad midiendo el impacto de un comercio libre mutilado, por lo que me atrevería a plantear la cuestión de qué impacto hubiera tenido el establecimiento del pleno comercio libre en 1765. De poder calcularse, la diferencia entre este mayor impacto potencial y el observado sería un indicador del coste de oportunidad del gradualismo, de una pérdida de ganancias generada en buena parte por la presión de los intereses comerciales privilegiados.

Política agraria. Los estudios disponibles indican un alcance limitado del resto de la política agraria. Sierra Morena, aunque se consolidó con nuevas poblaciones, no actuó como modelo de sociedad imitado (sobre todo tras el autillo inquisitorial de Olavide); los moderados repartos de tierra municipales experimentaron un funcionamiento irregular en algunos casos; hubo cambios de criterios sobre la libertad de arrendamientos; la anhelada Ley Agraria nunca se promulgó (para bien o para mal); se experimentaron nuevas técnicas agrícolas no siempre aplicables; las denuncias sobre los bienes de la Iglesia no se convirtieron en legislación y los mayorazgos continuaron en vigor. Aunque la moderada y persuasiva politica ilustrada no consiguió transformar las «estructuras agrarias» ni generalizar la figura del labrador independiente, es dificil mantener que constituyó un obstáculo al crecimiento agrario. Ante la escasez de instrumentos disponibles y a la vista de otras experiencias históricas españolas y foráneas, quizá sería conveniente admitir que muchos de los problemas básicos y seculares de la agricultura española estaban más allá del control directo del gobierno, aunque esto suponga contradecir las creencias firmemente asentadas de nuestros ilustrados.

Política industrial y comercial. Aunque con algún titubeo al principio y al final del periodo, ambas políticas ilustradas fueron pragmática y decididamen-

27 Fisher (1985 y 1987), Morineau (1985) y Tedde (1989).

28 Prados (1988), pp. 74-75, y Tedde (1989), pp. 207-209. 
te industrialistas, y hasta es probable que los estímulos que pudieron proporcionar a procesos en marcha de crecimiento industrial y comercial en diversas áreas fueran más intensos que los de la politica agricola. La medida más reiterada - las gracias, exenciones y franquicias - tenía una triple característica: constituía un estímulo directo al desarrollo de las fábricas, no fue discriminadora al generalizarse a todos los sectores y poseyó un marcado talante antifiscalista. La progresiva liberalización del proceso de fabricación industrial y la reforma de los gremios permitieron una mayor flexibilidad económica y la deslegitimación de tales instituciones privilegiadas. La declaración de honradez de los oficios abrió un portillo legal para la difuminación de los antiguos estamentos sociales. El fomento de la industria popular iba orientado a la pervivencia y ampliación del amplio Kauf system existente en España, a combatir la desocupación y mejorar los ingresos de las familias rurales. El retroceso en el apoyo a las fábricas reales estatales y la cesión de varias de ellas a compañías privadas pudo liberar algunos fondos y mejorar el clima industrial. La política comercial exterior tuvo en general un carácter ortodoxamente proteccionista en cuanto a la reserva del mercado interior y colonial, al favorecimiento de la introducción de materias primas foráneas y estableció el primer arancel general moderno en 1782 - con derechos entre el 15 y el 30 por ciento y algunas prohibiciones- que está reclamando un estudio detallado. Puede observarse, con cierta sorpresa, que varias de las tendencias básicas de la política comercial e industrial española se asemejan a las que continuaba adoptando Inglaterra a partir de un pragmático proteccionismo industrial sobre todo en la industria textil ${ }^{29}$, en base a una mayor libertad económica interior de facto que no se preocupaba tanto de abolir legalmente todas las regulaciones y privilegios - los gremios no fueron abolidos hasta 1835-, sino de ignorarlas y evadirlas provocando su deslegitimación y desuso ${ }^{30}$. Vuelvo a subrayar que no es posible deslindar, ni mucho menos cuantificar, el efecto de la acción del Estado sobre el crecimiento - tampoco cuantificado- comercial e industrial español de la época ilustrada, que si bien es cierto que se produjo en forma desigual también lo es que en algunas áreas alcanzó unas proporciones considerables: en 1792 - afirma Pierre Vilar ${ }^{31}$ — «con un consumo de algodón hilado equivalente al 16 por ciento de Inglaterra, Cataluña quedaba más cerca de aquel pais como nunca lo estuvo durante el siglo siguiente». Por su lado, Ricardo Franch ha encontrado una notable acumulación de capital de origen co-

\footnotetext{
29 O'Brien, Griffiths and Hunt (1991) y Davis (1968).

30 Mokyr (1987), pp. 221-228.

31 Vilar (1992), p. 357.
} 
mercial en la Valencia de la segunda mitad del setecientos ${ }^{32}$. Y nos podriamos extender con otros ejemplos. ¿Qué papel jugó el moderado gobierno ilustrado en todo ello? Me atreveria a concluir, tras una breve mirada a los ejemplos europeos, que si no hubo mayor crecimiento industrial no fue a causa del gobierno y que el crecimiento producido no fue a pesar del gobierno, sino que se vio favorecido por el conjunto de su acción.

Política de obras públicas y comunicaciones. Aunque más lenta de lo programado, tuvo algunas conocidas realizaciones en la red viaria, en los canales de transporte y de riego y en la reforma del servicio de Correos que pudieron, entre otros efectos, aligerar los costes de transacción ampliar los regadios, mejorar la comercialización de los excedentes agrarios y perfeccionar los abastecimientos hidráulicos ${ }^{33}$.

Politica financiera. Recientes investigaciones han dado un vuelco a la imagen de la Hacienda al borde del colapso al final del reinado de Carlos III. Pedro Tedde ha mostrado con detalle que a pesar de la rigidez del cuadro tributario el sistema fiscal estuvo próximo al equilibrio en los años finales, mantenía una proporción de impuestos directos e indirectos similar a la británica $-\mathrm{y}$ un sistema recaudatorio parejo-, sufrió un crecimiento moderado del gasto y de los ingresos públicos (basados en forma creciente en la multiplicación del comercio colonial) y gozaba de credibilidad y solvencia financiera - como se desprende de la positiva cotización de los vales reales-. Excluye un efecto crowding-out del sector público al considerar que el incremento de la inversión productiva derivada del comercio exterior se produjo simultáneamente con la utilización de recursos ociosos en activos financieros y que el aumento de las llegadas de plata más que provocar inflación generó una ampliación de la capacidad productiva y del comercio exterior ${ }^{34}$. Por otro lado, también se han producido nuevas interpretaciones en la historia financiera europea de la época al destacar, en las comparaciones entre Gran Bretaña y Francia, el fuerte aumento en las recaudaciones impositivas, la mayor carga fiscal per cápita y la superior proporción de la renta nacional absorbida por la Hacienda del primer país, a partir de un sistema basado en la imposición indirecta y en una administración eficiente ${ }^{35}$. Quizá un análisis comparativo sistemático del caso español con los países europeos de su entorno permitiria precisar aún más la sobriedad de las finanzas de Carlos III. Mientras tanto, es preciso indicar que entre 1765 y 1790 los ingresos ordinarios de carácter impositivo en valores corrientes cre-

\footnotetext{
32 Franch (1986), pp. 319.328.

33 Madrazo (1984).

34 Tedde (1989), pp. 215-217.

35 Mathias-O'Brien (1976), O'Brien (1988), Weir (1989) y Beckett y Turner (1990).
} 
cieron alrededor de un $32 \%$ en España, de un $56 \%$ en Francia y de un $74 \%$ en Inglaterra, y qué en términos per cápita el incremento pudo ser tres veces mayor en el último pais que en los otros dos ${ }^{36}$. Además de lo indicado en el cuadro 2 , encontramos que precisamente en 1788 mientras los intereses de la deuda española suponían alrededor de un $20 \%$ de los ingresos ordinarios, las deudas francesa y británica absorbian sobre un 62 y un $56 \%$, respectivamente ${ }^{37}$. Aunque haya que tomarlos con cautela, y reelaborarlos con deflactores homogéneos, los datos parecen evidenciar un reducido fiscalismo, un bajo nivel de endeudamiento y un decrecimiento relativo del coste del Estado para los españoles. Las consecuencias económicas de esta lectura simple de unos datos complejos no son inequivocas, aunque sólo sea por la razón de que la actual historiografía británica discrepa sobre el impacto a corto plazo de la creciente imposición - acerca del posible efecto retardador del crecimiento y de la «revolución industrial»- pero coincide en que a largo plazo fue un coste imprescindible para asegurar la prosperidad económica y la supremacía británica ${ }^{38}$. ¿Podríamos invertir la cuestión y plantearnos si el modesto fiscalismo español pudo tener claros efectos positivos a corto plazo sobre el crecimiento económico pero fue demasiado moderado en una visión a largo plazo para mantenerlo? ¿O la segunda alternativa estaba más allá de las posibilidades españolas? ¿La referencia es Inglaterra, o son otros países europeos? Naturalmente sólo deseo plantear algunos interrogantes, aunque también apuntar el posible interés de una discusión al revés de la tradicional y más cercana a las tendencias actuales de la historiografía europea.

\section{EPILOGO}

1. En vista de la amplitud, coherencia interna y razonabilidad de los objetivos de la política económica de Carlos III, me atrevería a proponer una generalización de la tesis expresada por Antonio Domínguez Ortiz y Angel Gar-

${ }^{36} \mathrm{El}$ dato del $32 \%$ lo he obtenido a partir de las cifras de Merino (1987) y Tedde (1989), calculando un ingreso medio de cinco años centrado en 1765 de 464.320 .000 reales de vellón corrientes y un ingreso medio de cinco años centrado en 1790 de 614.143 .000 reales. Los datos franceses y británicos tanto absolutos como per cápita de O'Brien (1976), pp. 604-605. En O'Brien (1988), p. 3, se ofrece un crecimiento de los ingresos impositivos británicos para el periodo del $64 \%$ que no cambiaría las conclusiones del análisis. Para la comparación entre la evolución de los ingresos per cápita he supuesto una tasa de crecimiento anual de la población española de un 4 por mil.

37 Weir (1989), tabla 1, p. 98, y fuentes de la tabla 1 de este trabajo.

38 Thomas-McCloskey (1981), pp. 93-94; Mokyr (1987), pp. 300-306; O'Brien (1988), pp. 7-8, y Beckett-Turner (1990), pp. 396-402. 
cía Sanz ${ }^{39}$ respecto a la política agraria ilustrada, y conceder al conjunto de la acción económica estatal del período examinado la consideración de primera experiencia moderna de política económica en sentido estricto aplicada en España. Con ello, mi principal intención no es reclamar la tolerancia debida a los pasos primerizos, sino sostener que a pesar de su relativa novedad, y de las obstrucciones que tuvo que superar, fue una experiencia notable y que parece resistir bien las comparaciones con otros ejemplos históricos españoles y con las politicas europeas contemporáneas.

2. En relación con sus dos objetivos básicos -el crecimiento de la $R i$ queza de la Nación y la Fortaleza de la Monarquía - la acción del Estado no puede considerarse significativamente como un fracaso. El efecto neto de las medidas económicas actuó como estímulo al crecimiento de la producción y los intercambios en el seno de una coyuntura económica alcista. También puede observarse un efecto corrosión de las instituciones privilegiadas tradicionales que se oponian a la flexibilidad social y al progreso y un efecto integración económico-política de la sociedad española, debiendo considerarse que las repercusiones de ambos efectos se extienden hacia el siglo xIX. Además el conjunto de las mejoras del marco institucional — combinadas con la estabilidad de la Monarquía - posiblemente favoreció los animal spirits de los agentes impulsores de las actividades económicas. Por último, situados en diciembre de 1788, se había producido un robustecimiento y centralización del Estado, se habia generado una mayor articulación de la sociedad española, se había conservado un gran imperio colonial - que alcanzó su máxima extensión en 1783 - y la Monarquia española parecia gozar de buena salud política y financiera a ojos de los contemporáneos. Asi pues, se habia avanzado notablemente en las máximas de más Estado y más Mercado, aunque es difícil -o quizá imposible- determinar si en grado suficiente.

3. Como ya se ha argumentado, el trasfondo de la tesis fiscalista no parece corresponderse bien con la situación geopolítica del xvill, ni con los volúmenes europeos relativos de tributación y de deuda, ni con las motivaciones del programa reformador. También se ha insistido en que existen serias dificultades analíticas para alcanzar un significado preciso por parte de la tesis del fracaso bienintencionado, y que en cualquier caso no hubo fracaso generalizado ni siquiera crisis financiera de algún relieve. Como suele ocurrir en los procesos de desarrollo, el crecimiento conseguido fue de carácter desequilibrado tanto desde un punto de vista territorial como sectorial.

4. Respecto a la visión cosmética he de remitirme adicionalmente a la

\footnotetext{
${ }^{39}$ Dominguez Ortiz (1976), pp. 418-420, y Garcia Sanz (1989), p. 630.
} 
crítica hirschmaniana a las tesis de los grilletes feudales (o de la futilidad) ${ }^{40}$, en la que se subraya la paradoja de que en este caso el pensamiento de inspiración marxista se transforma en defensor intransigente del capitalismo pleno en las etapas históricas precapitalistas de los paises periféricos. Según esta tesis, la causa principal del atraso en tales paises radica en la debilidad de las «burguesías» nacionales (y de los Estados que debían haber conquistado) al enfrentarse con las fuerzas sociales tradicionales y en su renuncia a eliminar las telarañas del antiguo orden de cosas. Pero el principal problema de esta visión es que el modelo de referencia para los países centrales nunca ha funcionado, pues la «burguesía» no ha cumplido su pretendida misión histórica en ningún lado. Así pues, ¿cómo la iban a cumplir nuestros pragmáticos políticos ilustrados o un moderado rey absoluto? En todo caso, si tenemos en cuenta que en la España de Carlos III no existian grupos sociales buscadores de «transformaciones estructurales» - sino más bien buscadores de rentas monopolísticas y de privilegios políticos que obstaculizaron las reformas-, la tesis cosmética española parece reflejar una cierta "pasión por lo imposible», pues en definitiva afirma que no se hizo lo que era politicamente imposible hacer, dadas las circunstancias. El pretendido cambio estructural previo era algo no deseado, pero también una imposibilidad política. Por el contrario, la menos espectacular vía reformista podia lograr ciertos resultados - moderados pero en absoluto desdeñables- hacia una sociedad más abierta y más próspera en diversas esferas.

5. A pesar de todo, Jovellanos y Cabarrús sólo estuvieron acertados en una de las dos pretensiones básicas de su Elogio a Carlos III. Como valoración positiva de la política económica del reinado concluido sus argumentos parecen consistentes (y este articulo es un intento de «verificar» dicha valoración). Sin embargo, ambos economistas ilustrados no lograron materializar el objetivo no escrito de su elogio: transformarlo en un operativo Exborto a Carlos IV. Circunstancias de diversa indole y gravedad imposibilitaron el empeño. La fuerza, la seducción y la tragedia de determinados acontecimientos históricos con frecuencia oscurecen o distorsionan la visión de los anteriores y, lo que es peor, hacen apreciarlos como meros preludios de los posteriores. Quizá sea hasta cierto punto inevitable, pero siempre deberíamos esforzarnos con diligencia esmerada para no caer en la simple trampa del post boc, ergo propter boc.

41 Hirschman (1989), pp. 125-132, y (1991), pp. 84-95. 


\section{BIBLIOGRAFIA}

ANEs, Gonzalo (1970): Las crisis agrarias en la España moderna, Madrid, Taurus.

- (1975): El Antiguo Régimen: Los Borbones, Madrid, Alianza.

__ (1989): «Sociedad y economía», en Ministerio de Cultura (1989), vol. II, pp. 1-138.

ArTola, Miguel (ed.) (1989): La economia española al final del Antiguo Régimen. IV. Instituciones, Madrid, Alianza.

BARBIER, J. A., y KLeIN, H. S. (1985): «Las prioridades de un monarca ilustrado: el gasto público bajo el reinado de Carlos III", Revista de Historia Económica, 3, pp. 473-491.

BECKETT, J. V., y TURNER, Michael (1990): «Taxation and economic growth in eigteenthcentury England», Economie History Review, XLIII, 3, pp. 377-403.

Cabarrús, Francisco (1789): Elogio de Carlos III, Rey de España y de las Indias, Madrid, Antonio Sancha.

CARrera, Isabel (1982): «El poder legislativo en la España del siglo xviII (1716-1808)», en Artola (1982), pp. 185-268.

CASTRO, Concepción de (1987): El pan de Madrid, Madrid, Alianza.

DAvis, Ralph (1966): «The Rise of Protection in England, 1689-1786», Economic History Review, XIX, 2, pp. 306-317.

Delgado, Josep M." (1986): «Libre comercio: Mito y realidad», en Martínez Vara (1987), pp. 69-84.

_ (1987): «El modelo catalán del sistema de libre comercio», en Fontana (1987), pp. 53-69.

__ (1989): «Floridablanca y el planteamiento de la politica agraria de Carlos III», en Ministerio de Agricultura (1989), pp. 639-661.

Deyon, Pierre, y Guignet, Ph. (1980): «The Royal Manufactures and Economic and Technological Progress in France before the Industrial Revolution», Joumal of European Economic History, IX, 3, pp. 611-632.

Dominguez OrTIZ, Antonio (1976): Sociedad y Estado en el siglo XVIII español, Barcelona, Ariel.

- (1988): Carlos III y la España de la Ilustración, Madrid, Alianza.

_ (1989): «Carlos de Borbón. Balance de un reinado», en Ministerio de Cultura (1989), vol. I, pp. 195-211.

EloRZA, Antonio (1970): La ideología liberal de la ilustración española, Madrid, Tecnos.

EQUIPO MADRID (1988): Carlos III, Madrid y la Ilustración. Contradicciones de un proyecto reformista, Madrid, Siglo XXI.

Fernandez Albaladejo, Pablo (1989): «La monarquia», en Ministerio de Cultura (1980), vol. I, pp. 1-89.

- (1992): Fragmentos de monarquía, Madrid, Alianza.

Fernandez DE PINEDO, Emiliano (1980): «Coyuntura y política económicas», en Fernández de Pinedo, E.; Gil Novales, A., y Dérozier, A.: Centralismo, Ilustración y Agonía del Antiguo Régimen (1715-1833), Barcelona, Labor, pp. 9.173.

Fernandez Diaz, Roberto (ed.) (1985): «España en el siglo xvil o los límites de una re. forma», en España en el siglo xviII, Barcelona, Crítica, pp. 17-53.

(1993): La España moderna. Siglo xvII, Madrid, Historia 16.

FISHER, John (1985): Commercial relations between Spain and Spanish America in the era of free trade, 1778-1796, Liverpool, Centre for Latin American Studies. 
(1987): «El impacto del comercio libre en América durante el último cuarto del siglo XviIIs, en Fontana (1987), pp. 29-38.

FONTANA, Josep (1971): La quiebra de la monarquía absoluta, Barcelona, Ariel.

- (1982): «Comercio colonial y crecimiento económico: revisión de hipótesis», en La economia española al final del Antiguo Régimen, III, Madrid, Alianza, pp. XI-XXXIV.

— (ed.) (1987): El comercio libre entre España y América Latina, 1765-1824, Madrid, Banco Exterior.

FRANCH, Ricardo (1986): Crecimiento Comercial y Enriquecimiento Burgués en la Valencia del Siglo xvII, Valencia, IVEI.

GARCtA-BAQUero, Antonio (1989): «La recuperación desde el atraso: política de fomentom, en El reformismo borbónico (1700-1789), Barcelona, Planeta, pp. 80-108.

GARCiA SANZ, Angel (1989): «La política agraria ilustrada y sus realizaciones», en Ministerio de Agricultura (1989), pp. 629-638.

GERSCHENKRON, Alexandre (1970): «El atraso económico en su perspectiva histórica», Atraso económico e industrialización, Barcelona, Ariel, pp. 5-48.

GONZALEZ EnCISO, Agustín (1980): Estado e industria en el siglo xyIII: la Fábrica de Guadalajara, Madrid, F.U.E.

- y Patricio Merino, José (1979): «The Public Sector and Economic Growth in Eighteenth Century Spain", Journal of European Economic History, VIII, 3, pp. 553. 592.

GonZÁlez GonZÁlez, M. J. (1990): «Campomanes y Jovellanos ante los problemas de la modernización del Antiguo Régimen», Hacienda Pública Española, Monografías núm. 2, pp. 13.25.

HERR, Richard (1964): España y la revolución del siglo xvill, Madrid, Aguilar.

- (1989a): «Carlos III: el rey, el pueblo, el futuro», en Ministerio de Cultura (1989), vol. III, pp. 137-152.

- (1989b): Rural Change and Royal Finances at the End of the Old Regime, Berkeley, Univ. California Press.

Hirschman, Albert (1945): National Power and the Structure of Foreign Trade, California, University of California.

- (1971): A Bias for Hope, New Haven, Yale University.

- (1978): Las pasiones y los intereses, México, FCE.

- (1988): Come complicare l'economia, Bolonia, Il Mulino.

- (1989): Enfoques alternativos sobre la sociedad de mercado, México, FCE.

- (1991): The Retoric of Reaction, Cambridge (Mass.), Harvard University Press.

HuTchison, T. W. (1971): Economía positiva y objetivos de politica económica, Barcelona, Vicens-Vives.

JONES, E. L. (1987): El milagro europeo, Madrid, Alianza.

Jovellanos, Gaspar Melchor de (1789): Elogio de Carlos Tercero, Madrid, Viuda de Ibarra.

LYNCH, John (1991): El siglo XVIII, Barcelona, Crítica.

Llombart, Vicent (1976): Pensamiento y teoria de la política económica del Conde de Campomanes, Valencia, Universidad de Valencia.

- (1981): «El sorgiment de les Societats Econòmiques i llur conflicte amb les institutions comercials», Recerques, 11, pp. 187-194.

- (1992): Campomanes, economista y político de Carlos III, Madrid, Alianza.

Madrazo, Santos (1984): El sistema de transportes en España, 1750-1850, Madrid, CICCP. 
Maravall, José Antonio (1991): Estudios de la bistoria del pensamiento español (siglo XVIII), Madrid, Mondadori.

MaRInez VARA, T. (ed.) (1987): Mercado y desarrollo económico en la España moderna, Madrid, Siglo XXI.

Mathias, Peter, y O'Brien, Patrick (1976): «Taxation in Britain and France, 1715. 1810», Journal of European Economic History, 5, 3, pp. 601-650.

Matilla, Antonio (1956): Catálogo de la Colección de órdenes generales de Rentas, tomo I, Madrid, MEL.

Merino, José Patricio (1987): Las cuentas de la Administración central española, 1750-1820, Madrid, IEF.

MiNISTERIO DE AGRICULTURA (1989): Estructuras agrarias y reformismo ilustrado en la España del siglo XVII, Madrid, Publicaciones del Min. de Agric.

Ministerio DE Cultura (1989): Actas del Congreso Internacional sobre "Carlos III y la Ilustración», 3 vols., Madrid, Min. de Cultura.

MOKYR, Joel (1987): «La revolución industrial y la nueva historia económica (I)», Revista de Historia Económica, V, 2, pp. 203-241.

(1987): «Has the industrial revolution been crowded out? Some reflections on Crafts and Williamsonm, Explorations on Economic History, 24, pp. 293-317.

Morineau, Michel (1985): Incroyables gazettes et fabuleux métaux, Nueva York, Cambridge University Press.

Novísima Recopilación de las Leyes de España (1805-1807), Madrid (s.i.), 6 vols.

O'Brien, Patrick (1988): «The political economy of British taxation, 1660-1815», Economic History Review, XLI, 1, pp. 1-32.

-; GrIfFITHS, Trevor, y HUNT, Philip (1991): «Political componentes of the industrial revolution: Parliament and the English cotton textile industry, 1660-1774», Economic History Review, XLIV, 3, pp. 395-423.

Perdices, Luis (1993): Pablo de Olavide (1725-1803). El ilustrado, Madrid, Universidad Complutense.

Prados de la Escosura, Leandro (1988): De Imperio a Nación, Madrid, Alianza.

Rodriguez LabandeIRA, José (1982): «La política económica de los Borbones», en Artola (1982), pp. 108-184.

SÁnCHEZ, Felipa (1988): Extensión de cultivos en España en el siglo XVIII, Madrid, Siglo XXI.

SÁnchez, S. (1792): Colección de pragmáticas, cédulas, provisiones, circulares, autos... en el reynado de Carlos III, Madrid, Sancha.

SMITH, Adam (1776): Investigación sobre la naturaleza y causa de la riqueza de las naciones, México, FCE, 1958.

SteIN, Stanley J. (1989): «Política mercantil española y el comercio con Francia en la época de Carlos III», Ministerio de Cultura (1989), vol. II, pp. 219.280.

Tedde de LorCa, Pedro (1988): El Banco de San Carlos (1782-1829), Madrid, Banco de España-Alianza.

- (1989): «Política financiera y política comercial en el reinado de Carlos III», en Ministerio de Cultura (1989), vol. II, pp. 139-217.

Thomas, R. P., y McCloskey, D. N. (1981): «Overseas trade and empire, 1700-1860m.

—; Floud, R., y MCCloskey, D. N. (1981): The economic bistory of Britain since 1700, Cambridge, CUP, pp. 87-102.

Tilly, Charles (1992): Coerción, capital y los Estados europeos, 990-1990, Madrid, Alianza. 
Tiroco, Santiago, y Fradera, Josep M.* (1987): «A modo de primeras conclusiones», en Fontana (1987), pp. 315-324.

VeldE, François, y WeIR, David (1992): «The Financial Market and Governement Debt Policy in France, 1746-1793», Journal of Economic History, 52, 1, pp. 1-39.

VILAR, Pierre (1966): Catalunya disn IEspanya moderna, Barcelona, Ediçions 62.

- (1982): «La España de Carlos III», en España a finales del siglo XVII, Tarragona, Hemeroteca de Tarragona.

- (1992): «Las transformaciones del siglo XvIII», en Nadal, Joaquín y Wolf, Philippe (eds.): Historia de Cataluña, Barcelona, Oikos-tau, pp. 329-358.

VOLTES, Pedro (1987): «La política económica», en La época de la Ilustración, vol. I, Madrid, Espasa-Calpe, pp. 213-245.

WeIR, David (1989): «Tontines, Public Finance, and Revolution in France and England, 1688-1789", Journal of Economic History, XLIX, 1, pp. 95-124.

WRIGLEY, E. A. (1992): Gentes, ciudades y riqueza, Barcelona, Crítica. 